\title{
Isozyme Profiles and Protein Patterns in Specific Organ Damage ${ }^{1}$
}

\author{
Herbert H. Cornish, Mary L. Barth, and Vernon N. Dodson \\ The University of Michigan, Department of Industrial Health, \\ School of Public Health, Ann Arbor, Michigan 48104 \\ Received April 26, 1969
}

\begin{abstract}
Isozyme Profiles and Specific Organ Damage. Cornish, Herbert H., Barth, MARy L., and Dodson, Vernon N. (1970). Toxicol. Appl. Pharmacol $16,411-423$. Serum lactic dehydrogenase isozymes have bcen utilized as a means of detecting specific organ damage in rats. The serum LDH isozyme patterns seen in response to liver or kidney damage are markedly different, thus these patterns were utilized to identify the damaged organ. Liver damage resulted in increased activity of the serum LDH-5 isozyme while kidney damage produced increased activity of LDH-1 and LDH-2. The ip injection of mercuric chloride $\left(\mathrm{HgCl}_{2}\right)$ resulted in elevated activity of LDH-1 and LDH-2, characteristic of kidney damage, after doses as low as $2 \mathrm{mg} / \mathrm{kg}$. In a time sequence study following the injection of $4 \mathrm{mg} \mathrm{HgCl} / \mathrm{kg}$ body weight, there was an early elevation of LDH-5 suggestive of liver damage. This was followed approximately 12 hours after injection by marked increase of LDH-1 and LDH-2 characteristic of kidney damage. An alteration of the serum protein electrophoretic pattern was also noticed in $\mathrm{HgCl}_{2}$ treated animals. This technique of studying serum isozyme patterns may become a valuable tool in the detection of organ damage produced by toxic compounds.
\end{abstract}

Although the use of isozyme patterns, or zymograms, has become relatively common as an aid in clinical diagnosis, the technique has not yet been widely used in toxicology. Reeves et al. (1967) have reported the use of starch gel electrophoresis in the study of chemically induced pneumoconioses in experimental animals. The present study was inaugurated as the initial study in a three-phase program; to determine the serum isozyme response to specific organ damage, to relate isozyme response to the effects of compounds whose specific organ damage is relatively well defined, and to utilize these techniques in the study of toxic substances whose sites of organ damage are not yet clarified. This report presents the findings relating to the usefulness of such a technique and evaluates a number of variables which may have a profound effect upon the data. In addition, the isozyme response to various amounts of $\mathrm{HgCl}_{2}$ was investigated.

\section{METHODS}

All animals utilized in the present study were male Sprague-Dawley ${ }^{2}$ rats weighing from 200 to $300 \mathrm{~g}$. Animals were maintained on an ad libitum diet of rat chow ${ }^{3}$ and water.

${ }^{1}$ Portions of this paper were presented at the 1969 meeting of the Society of Toxicology.

${ }^{2}$ Spartan Research Animals, Inc., Haslett, Michigan.

3 Rockland Rat Chow. 
Individual organs were damaged by the following procedure. Animals were anesthetized with ether, and the abdominal cavity was opened by a minimal incision. The relatively narrow tip of a conical centrifuge tube containing dry ice and ethanol was applied to a specific organ, where it rapidly froze a small area of tissue. The organ being frozen was held apart from other internal organs until the frozen area was completely thawed. The incision was then sutured. Sham operated animals were utilized for control studies. Blood was collected 4 hours later by open chest heart puncture using vacutainers. The serum was separated, divided into small samples, and quick-frozen in dry ice and ethanol. Samples were generally used within 2 weeks after collection. For the enzymes reported here, activity was relatively stable over this time period.

LDH isozymes were separated by electruphoresis on a vertical $5 \%$ polyacrylamide gel using a recirculated $0.038 \mathrm{~m}$ glycine buffer brought to $\mathrm{pH} 10$ with $\mathrm{NaOH}$. Use of this buffer results in all 5 isozymes migrating anodally. The isozymes were made visible with nitroblue tetrazolium (NBT) according to the method of Allen (1961), except that $d l$ lactate was substituted for $l$-lactate, one-fourth as much NBT was used, and potassium cyanide was omitted. These modifications did not affect the staining intensity or specificity of the stain as utilized in these studies. The isozymes are numbered according to the recommendation of the Standing Committee on Enzymes of the International Union of Biochemistry (Webb, 1964); i.e., the fastest anodally migrating isozyme is LDH-1. Although a number of other enzyme patterns have been investigated, only the results obtained with LDH zymograms and serum protein patterns will be presented here. Serum proteins were separated by the same electrophoretic technique utilizing a trisEDTA-borate buffer, $\mathrm{pH}$ 8.8. Proteins were stained with $1 \%$ Buffalo Blue Black (Amido Schwarz) in methanol-acetic acid-water (5:1:4 by volume).

The stained gel strips were scanned by reflectance using a Joyce Chromoscan. The area under each peak was measured with an integral counter. Since it is difficult to obtain comparable intensities of gel staining even under standardized conditions, the total LDH activity of each serum sample was determined spectrophotometrically according to the method of Wroblewski and La Due (1955). The activity of individual isozymes was taken as that percentage of the total activity corresponding to the percentage of the total area under their respective peaks. Normal animals $(N)$ were included on each gel for comparative purposes since in order to scan the gel it was necessary in some instances to shorten staining time in order to prevent bands of high activity from overstaining. This accounts for much of the obvious difference in staining intensity of LDH bands of normal animals on the various gels.

In one experimental group, after an initial sample of blood had been obtained by careful heart puncture, a clean vacutainer was put on the needle which had been kept in the heart. The septum of the heart was punctured about 12 times with the needle, and as much additional blood collected as possible. After most of the serum had been separated from the normal blood sample, the clot was stirred vigorously with a disposable pipette to cause marked hemolysis, and the hemolyzed serum was collected. Thus, the effects of hemolysis and heart damage by repeated puncture could be compared with normal serum samples from the same rat.

For a study of red blood cell LDH, uncontaminated by serum, blood was collected in heparinized vacutainers. The plasma was removed and the erythrocytes washed 3 times with $0.9 \% \mathrm{NaCl}$ before hemolysis with approximately 3 volumes of distilled water. The 
hemolysate was centrifuged, and the supernatant was preserved by rapid freezing in dry ice and ethanol.

Groups of rats were initially injected ip with $6,4,2,0.5$, and $0.1 \mathrm{mg} / \mathrm{kg} \mathrm{HgCl}_{2}$ and sacrificed 24 hours later for serum isozyme studies. Additional groups were then injected ip with $4 \mathrm{mg} / \mathrm{kg}$ and sacrificed at various time intervals after injection. Serum was collected and stored as described above. Liver and kidney sections were also taken for histopathologic evaluation.

\section{RESULTS}

The serum LDH isozyme patterns of typical normal and sham-operated rats, and rats whose liver or kidney had been damaged by freezing are shown in Fig. 1. The

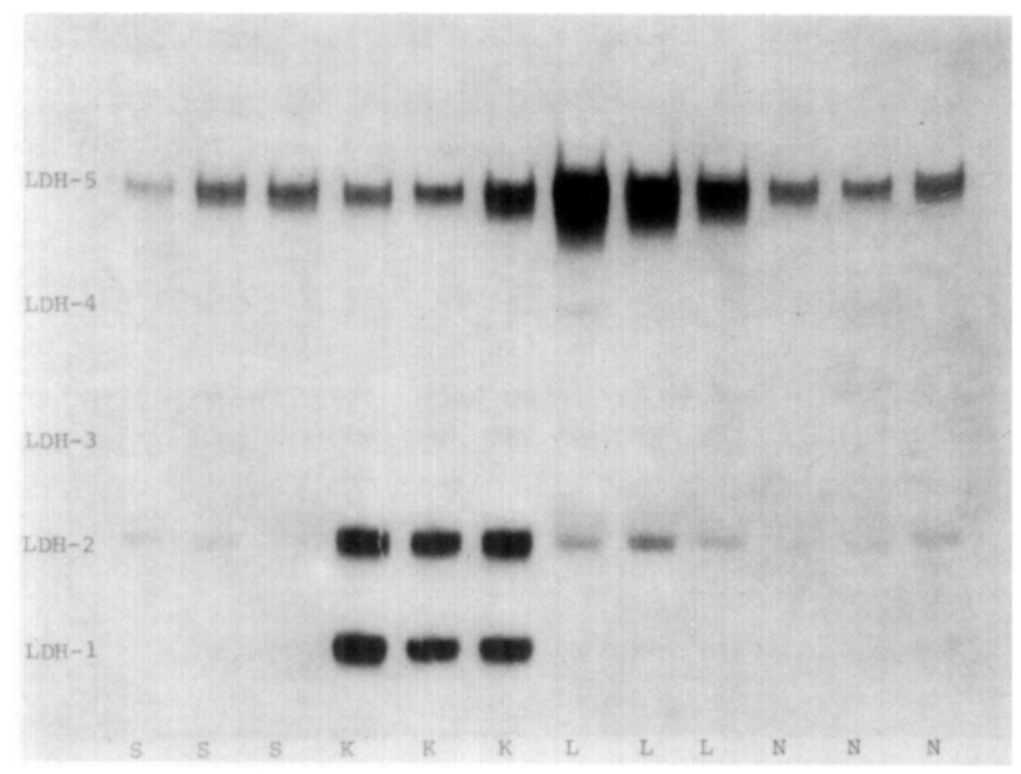

FIG. 1. The effects of kidney damage $(K)$, liver damage $(L)$, and sham operation $(S)$ on serum LDH zymograms. Normal rat sera $(N)$.

quantitative evaluation of such changes in a larger number of rats is given in Table 1. Sham operation had little, if any, effect on the relative amount of each isozyme in serum, but after organ damage, striking changes were seen. Liver damage greatly increased the intensity of LDH-5, as much as 10 times control values. The increased quantity of LDH-2 in liver damaged rats as recorded in Table 1, but not so evident in Fig. 1, partially reflects the difficulty of obtaining reproducible results from one gel to another when bands are not clearly delimited. Liver damage also causes some increase in the activity of LDH- 3 and -4 .

In Table 1, the kidney-damaged animals show almost comparable values for LDH-1, -2 , and -5 . However, 2 of the 3 samples in Fig. 1 show considerably less activity in LDH-5 than in LDH-1 and -2, an example of rat-to-rat variation. However, the major increases resulting from kidney damage are in LDH-1 and -2 , which are weak bands in sera from normal rats. LDH-3 shows a small but significant increase in activity and a very 
TABLE 1

The Effects of Sham Operation and Organ Damage on Serum LDH Activity (UNITS/ML) ${ }^{a}$

\begin{tabular}{|c|c|c|c|c|c|}
\hline & Control & $\begin{array}{c}\text { Sham } \\
\text { operated }\end{array}$ & $\begin{array}{l}\text { Excessive } \\
\text { heart } \\
\text { puncture }\end{array}$ & $\begin{array}{l}\text { Frozen } \\
\text { kidney }\end{array}$ & $\begin{array}{c}\text { Frozen } \\
\text { liver }\end{array}$ \\
\hline LDH-5 & $220 \pm 19$ & $212 \pm 29$ & $529 \pm 98$ & $598 \pm 82^{b}$ & $1864 \pm 269^{\circ}$ \\
\hline LDH-4 & $3 \pm 1$ & $1 \pm 1$ & $21 \pm 8$ & $13 \pm 5$ & $39 \pm 16^{c}$ \\
\hline LDH-3 & $7 \pm 2$ & $14 \pm 4$ & $54 \pm 16^{b}$ & $51 \pm 11^{c}$ & $47 \pm 16^{b}$ \\
\hline LDH-2 & $80 \pm 11$ & $124 \pm 16$ & $276 \pm 77$ & $574 \pm 92^{d}$ & $380 \pm 66^{b}$ \\
\hline LDH-1 & $19 \pm 3$ & $28 \pm 5$ & $53 \pm 15$ & $547 \pm 70^{d}$ & $69 \pm 14$ \\
\hline$\frac{\mathrm{LDH}-1}{\mathrm{LDH}-2}$ & $0.27 \pm 0.03$ & $0.24 \pm 0.04$ & $0.19 \pm 0.01$ & $0.99 \pm 0.03^{d}$ & $0.20 \pm 0.02$ \\
\hline Total S-LDH & $328 \pm 23$ & $380 \pm 37$ & $728 \pm 220$ & $1728 \pm 238^{e}$ & $2400 \pm 352$ \\
\hline No. of rats & 27 & 10 & 4 & 11 & 11 \\
\hline
\end{tabular}

- Statistical Method: Duncan's New Multiple Range Test (Kramer, 1956). Values are given as mean $\pm \mathrm{SE}$.

${ }^{b}$ Significantly different from control and sham operated means only, $P<0.05$.

${ }^{c}$ Significantly different from control and sham operated means only, $P<0.01$.

"Significantly different from all other means, $P<0.01$.

e Significantly different from all other means, $P<0.05$.

faint new band is present between LDH-3 and - 4 in most rats with severe kidney damage. This new band of LDH activity is also present in isozyme patterns of kidney homogenate. The relationship of this band to the five LDH isoenzymes is not clear.

The zymograms of serum obtained from severely hemolyzed blood and after repeated heart puncture were compared with zymograms of control serum samples (Fig. 2).

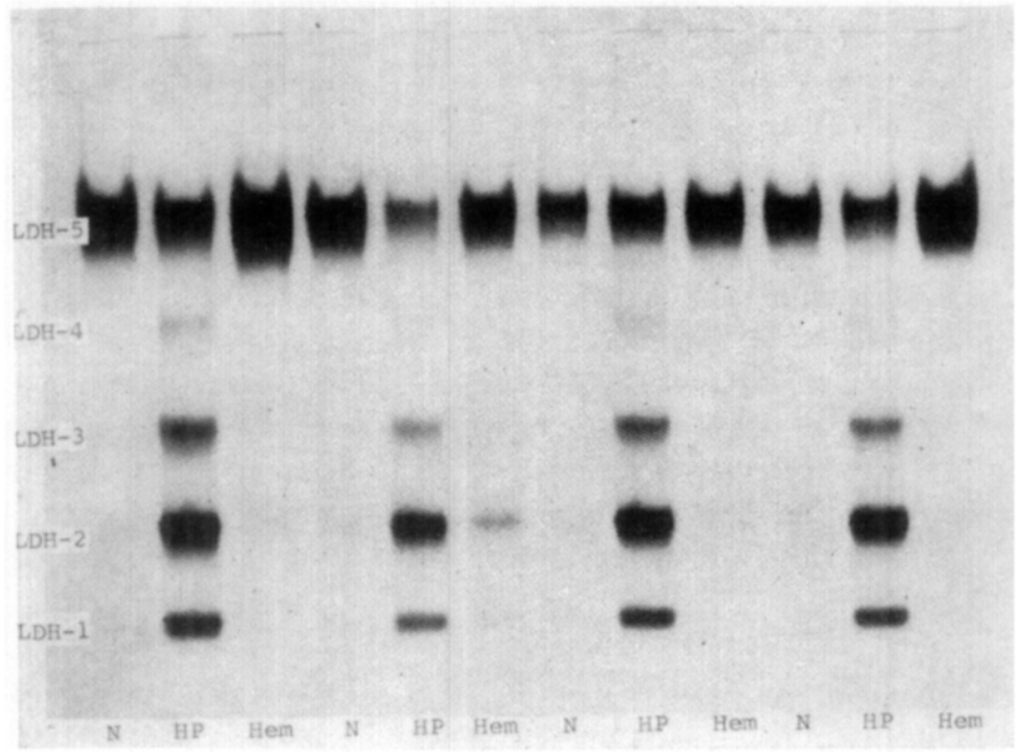

FIG. 2. Effects of repeated heart puncture and hemolysis on serum LDH zymograms. Normal rats $(N)$, multiple heart puncture $(H P)$, severe hemolysis $(H e m)$. 
Severe hemolysis increased the intensity of LDH-5. Heart damage by repeated puncture primarily increased the serum concentrations of LDH-1, -2, and -3 . It also seems to

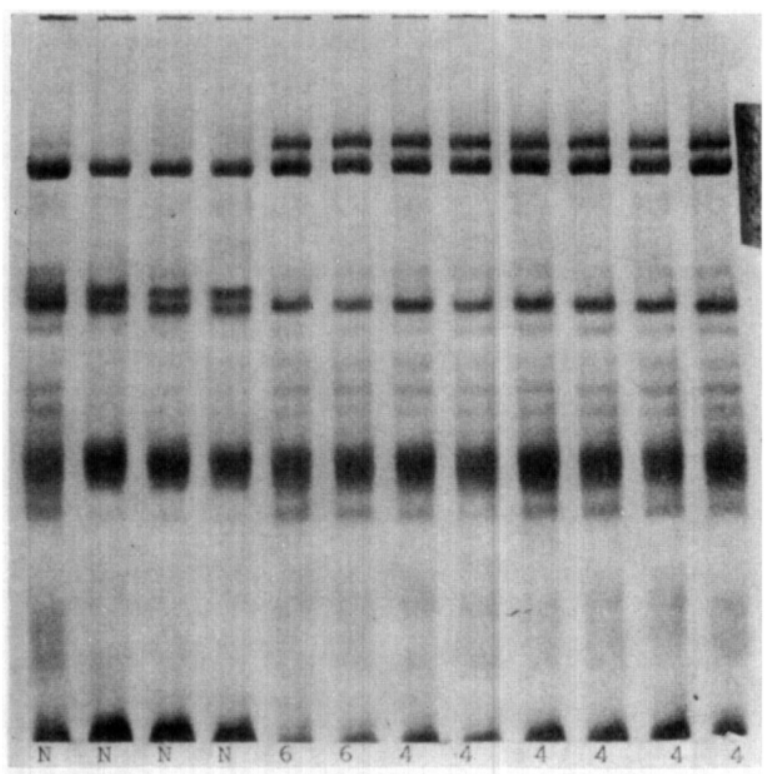

FIG. 3. Serum protein patterns from normal rats $(N)$ and rats injected ip with 6 or 4 mg of mercuric chloride per kilogram of body weight. Blood was collected 24 hours after injection.

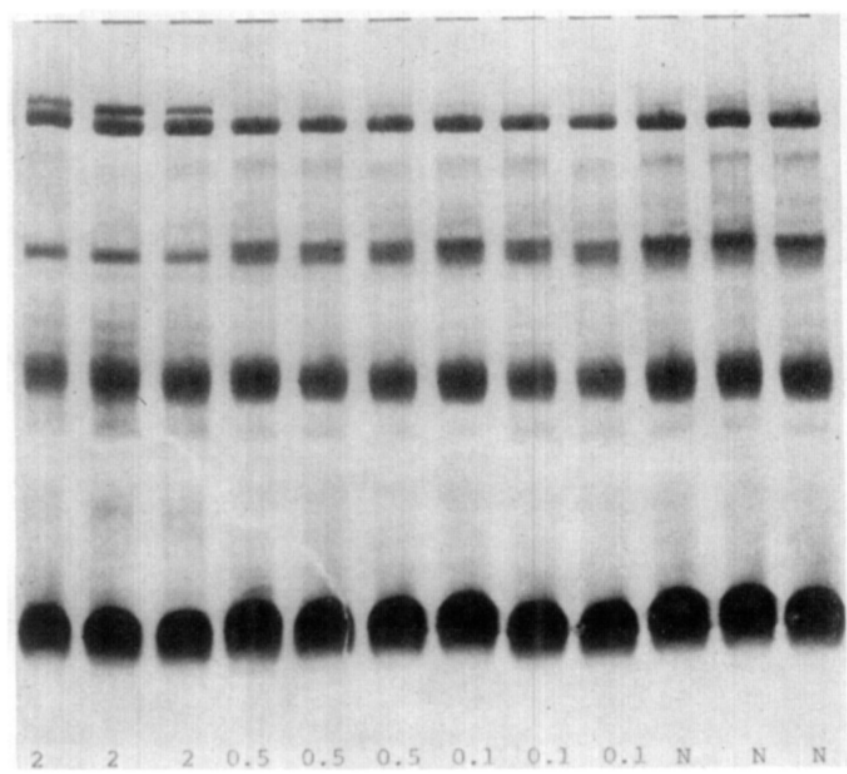

Fig. 4. Serum protein patterns from normal rats $(N)$ and rats injected ip with $2,0.5$, or $0.1 \mathrm{mg}$ of mercuric chloride per kilogram of body weight. Blood was collected 24 hours after injection.

intensify LDH-4 and -5 to a lesser degree. Several animals shown in Fig. 2 appear to have less densely staining bands of LDH-5 after heart damage; however, the average 
value for a different group of rats shown in Table 1 is larger, albeit not significantly, than the average for controls.

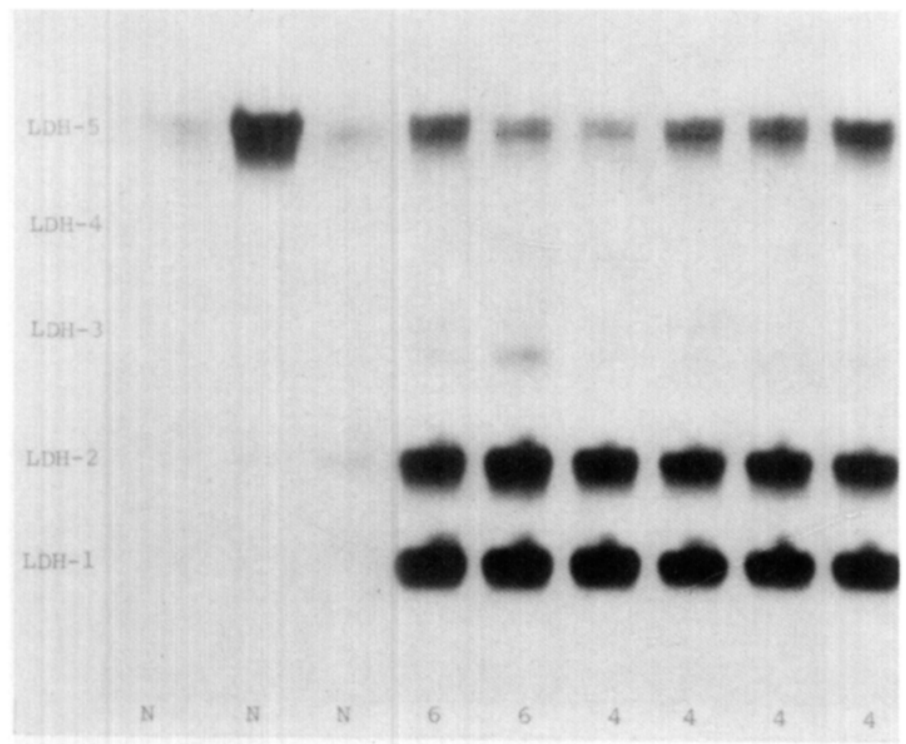

FIG. 5. Serum LDH zymograms from normal rats $(N)$ and rats injected ip with 6 or $4 \mathrm{mg}$ of mercuric chloride per kilogram of body weight. Blood was collected 24 hours after injection.

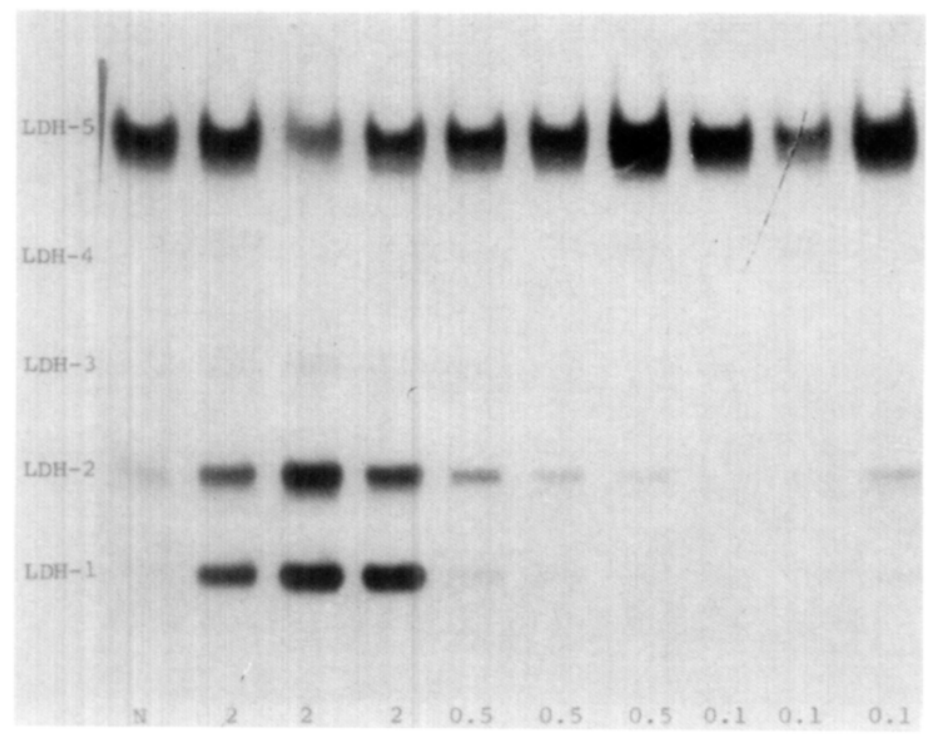

FIG. 6. Serum LDH zymograms from normal rats $(N)$ and rats injected ip with $2,0.5$, or $0.1 \mathrm{mg}$ of mercuric chloride per kilogram body weight. Blood was collected 24 hours after injection.

Protein stained electrophoretic patterns of the sera of rats injected with $6,4,2,0.5$, or $0.1 \mathrm{mg} / \mathrm{kg}$ of $\mathrm{HgCl}_{2}$ are shown in Figs. 3 and 4 . All samples were collected 24 hours after dosing. Animals receiving the higher doses of $\mathrm{HgCl}_{2}$ had an additional band of 
protein in the $\gamma$-globulin region as reported by Lawford (1961). A very weak band is noticeable at this point in some control animals. In most cases, this seemed to be accompanied by the loss of a band in the $\beta$-globulin area. For this same group of rats, the serum LDH isozyme patterns are presented in Figs. 5 and 6. The LDH pattern seen after 2 or more $\mathrm{mg} / \mathrm{kg}$ of $\mathrm{HgCl}_{2}$ was characteristic of kidney damage in that the intensity of bands 1 and 2 were markedly elevated and approximately equal (Table 2). The intensity of band 5 was slightly elevated by these doses of $\mathrm{HgCl}_{2}$, being comparable to values found with damaged kidney and not exhibiting the marked elevations noted with liver damage. At the 0.5 and $0.1 \mathrm{mg} / \mathrm{kg}$ dose, only 3 of the 6 patterns shown in Fig. 5 could be scanned for quantitation; thus LDH- 5 is indicated as being significantly different from normals at the $95 \%$ level. Visual inspection of the total gel would suggest that this is not a characteristic finding.

TABLE 2

Serum LDH Activity (Units/ML) 24 Hours After the InTRAPeritoneal INJeCtion of MERCURIC CHLORIDE

\begin{tabular}{lcccc}
\hline & Normal & $\begin{array}{c}4 \text { or } 6 \\
\mathrm{mg} / \mathrm{kg}\end{array}$ & $2 \mathrm{mg} / \mathrm{kg}$ & $\begin{array}{c}0.5 \mathrm{or} 0.1 \\
\mathrm{mg} / \mathrm{kg}\end{array}$ \\
\hline LDH-5 & $220 \pm 19$ & $885 \pm 54^{c}$ & $478 \pm 32^{c}$ & $423 \pm 73^{b}$ \\
LDH-4 & $3 \pm 1$ & $53 \pm 10^{c}$ & $9 \pm 4$ & $5 \pm 3$ \\
LDH-3 & $7 \pm 2$ & $195 \pm 56^{b}$ & $37 \pm 10$ & $20 \pm 3$ \\
LDH-2 & $80 \pm 11$ & $1558 \pm 141^{c}$ & $328 \pm 37$ & $75 \pm 9$ \\
LDH-1 & $19 \pm 3$ & $1512 \pm 92^{c}$ & $349 \pm 44^{c}$ & $24 \pm 4$ \\
LDH-1/LDH-2 ratio & $0.27 \pm 0.03$ & $1.01 \pm 0.04^{c}$ & $1.07 \pm 0.05^{c}$ & $0.33 \pm 0.02$ \\
Total & $328 \pm 23$ & $4308 \pm 262^{c}$ & $1202 \pm 88^{c}$ & $548 \pm 69$ \\
No. of rats & 27 & 6 & 6 & 3 \\
\hline
\end{tabular}

a Statistical Method: Dunnett's multiple $t$ test for unequal variances (Dunnett, 1964). Values are given as mean $\pm \mathrm{SE}$.

${ }^{b}$ Significantly different from the control with $P<0.05$.

c Significantly different from the control with $P<0.01$.

Histopathologic examination of kidney showed acute tubular necrosis and edema in animals receiving 4 or $6 \mathrm{mg} / \mathrm{kg}$ of $\mathrm{HgCl}_{2}$. A dose of $2 \mathrm{mg} / \mathrm{kg}$ resulted in extensive hyaline degeneration of the tubular epithelium with some hydropic degeneration. Rats receiving $0.5 \mathrm{mg} / \mathrm{kg}$ had cloudy swelling and minimal hydropic degeneration of the tubular epithelium. Animals receiving $0.1 \mathrm{mg} / \mathrm{kg}$ also had slight evidence of hydropic degeneration of the tubular epithelium, sufficient in most cases to distinguish them from controls. These histopathologic findings correlate rather closely with the LDH isozyme patterns for these groups of animals except at the lower dose levels where isozyme patterns did not reflect the minimal hydropic degeneration of tubular epithelium.

The time sequence of these changes in rat sera was studied in a group of animals which received $4 \mathrm{mg} / \mathrm{kg}$ of $\mathrm{HgCl}_{2}$ ip and was sacrificed at varying times after treatment. The protein patterns are shown in Figs. 7 and 8 . The intensified protein band in the $\gamma$-globulin region at the top of the figures is not present until 8 to 12 hours after injection, and correlates rather closely with the disappearance, or blurring, of one of the two distinct protein bands normally present just below this area. One of the 3 samples shown at 
4 hours is unusual and represents either an abnormal response of this animal to $\mathrm{HgCl}_{2}$ or an abnormal protein pattern prior to the study. Additional patterns show that this

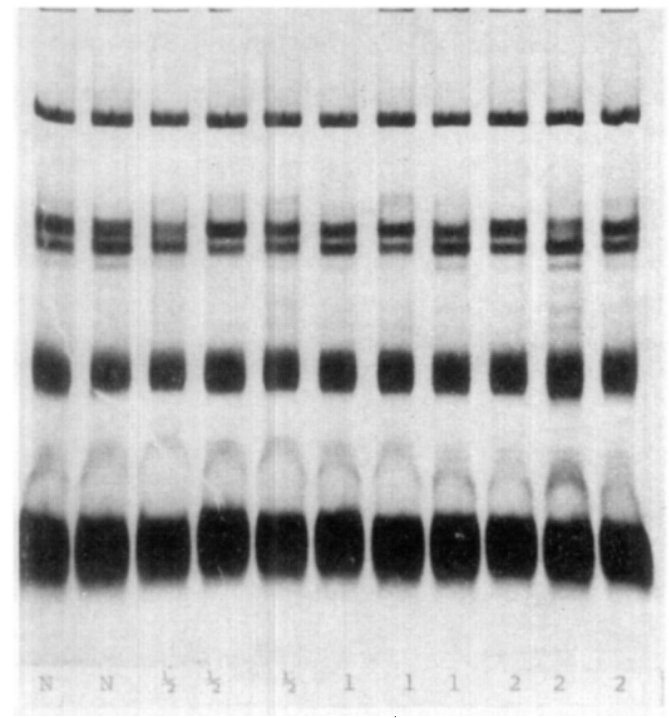

FIG. 7. Serum protein patterns of normal rats $(N)$ and rats injected ip with $4 \mathrm{mg}$ of mercuric chloride per kilogram of body weight. Blood samples were collected $\frac{1}{2}, 1$, and 2 hours after the injection.

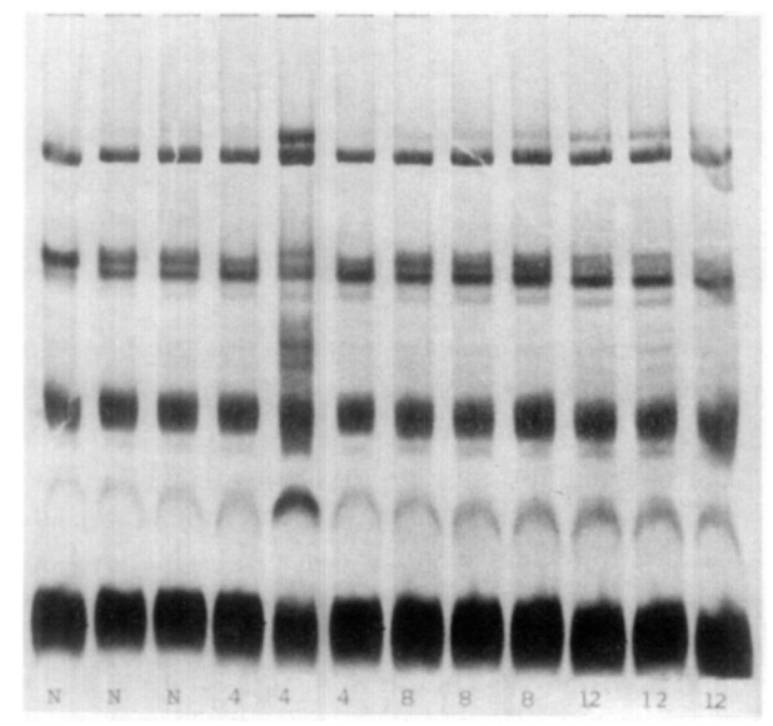

FIG. 8. Serum protein patterns of normal rats $(N)$ and rats injected ip with $4 \mathrm{mg}$ of mercuric chloride per kilogram of body weight. Blood was collected 4,8 , and 12 hours after the injection.

protein is still present 48 hours after treatment and is definite but decreasing in concentration 72 hours after treatment. Figures 9 and IO show the LDH isozyme patterns as they develop with time. The corresponding numerical data appear in Table 3 . Twelve 
hours after the ip injection of $\mathrm{HgCl}_{2}$, the marked increase in intensity of LDH-1 and LDH-2 characteristic of kidney damage is quite pronounced. An interesting point is

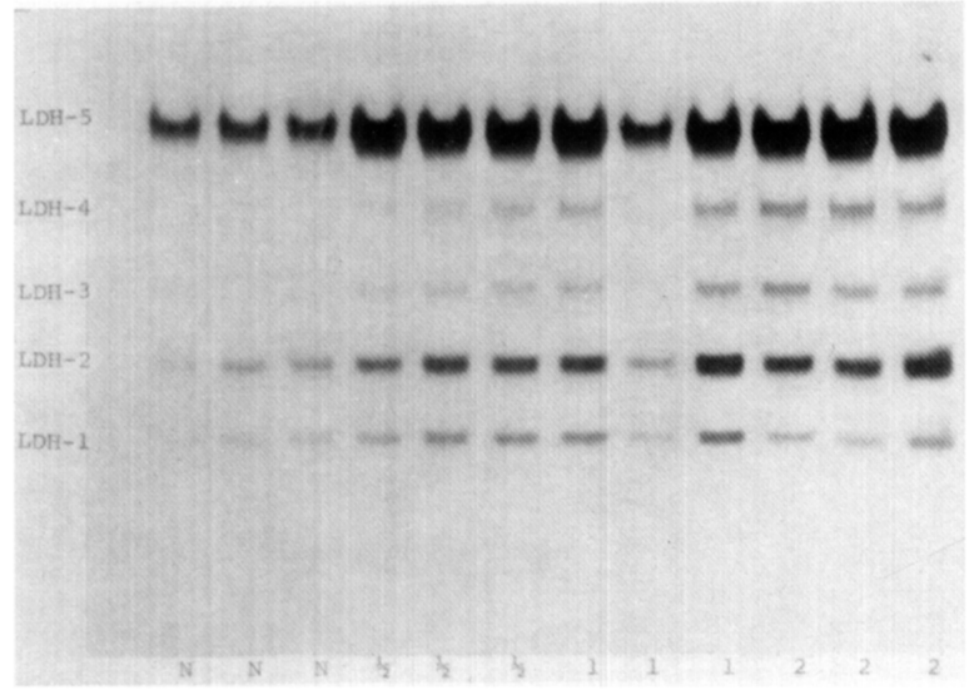

FIG. 9. Serum LDH zymograms from normal rats $(N)$ and rats injected ip with $4 \mathrm{mg}$ of mercuric chloride per kilogram of body weight. Blood was collected $\frac{1}{2}, 1$, and 2 hours after the injection.

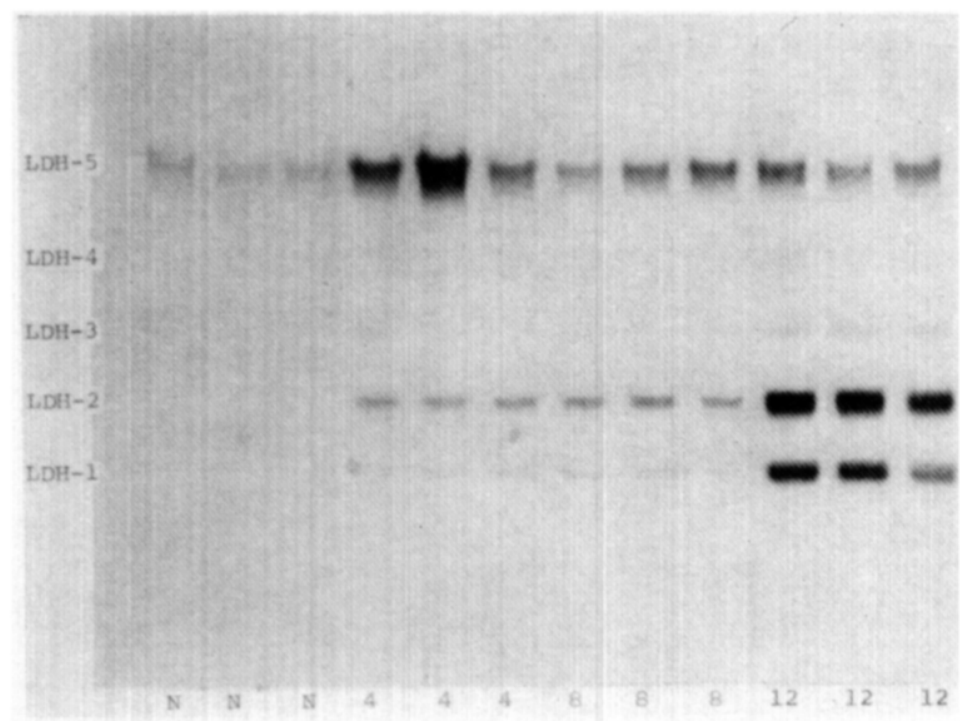

FIG. 10. Serum I.DH zymograms from normal rats $(N)$ and rats injected ip with $4 \mathrm{mg}$ of mercuric chloride per kilogram of body weight. Blood was collected 4,8 , and 12 hours after the injection.

the very early ( $30 \mathrm{~min}-2$ hours) appearance of an increased intensity primarily in LDH-5, similar to that seen in liver-damaged rats. Slight increases in the intensity of all other bands, particularly 2 , correspond with the isozyme pattern for liver damage as shown in Table 1. 


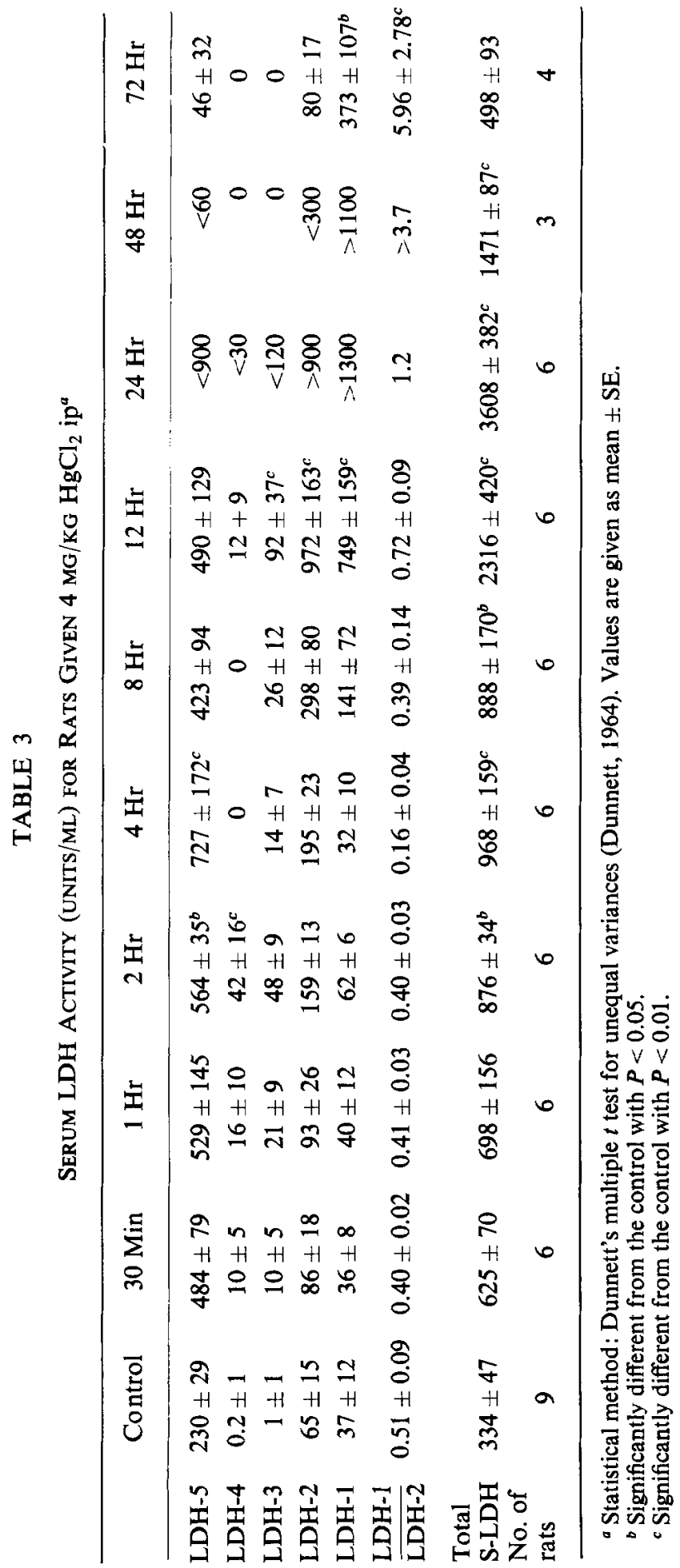


Total serum LDH activity rose rather rapidly (Table 3 ) and then remained relatively constant up to 8 hours after injection. It increased again at 12 hours and apparently reached a peak approximately 24 hours after treatment.

Table 3 also shows the activity of the various isozymes at 48 and 72 hours after exposure. The data for 24 and 48 hours are indicated as approximate in the table since with these particular patterns it was not possible to obtain quantitative scanning. Reducing the amount of sample used so that the darkest LDH band could be scanned resulted in no detectable staining in some of the other bands. However, the ratio of intensities of LDH-1 to LDH-2 is near 1.0 at 24 hours. It is interesting to note that this ratio increases to at least 3.9 and $6.0,48$ and 72 hours after mercuric chloride treatment. In Fig. 11, these changes in the ratio of LDH-1 to LDH-2 48 and 72 hours after treatment

FIG. 11. Serum LDH zymograms from normal rats $(N)$ and rats injected ip with $4 \mathrm{mg}$ of mercuric chloride per kilogram of body weight. Blood was collected 48, 72, and 192 hours after the injection.

are quite apparent. The probable significance of these findings will be discussed. Although LDH-5 is quite low in the 48- and 72 -hour groups, the rather conservative statistical test employed does not show significance at the $95 \%$ level.

Histopathologic examination of liver sections taken 30 min to 4 hours after $\mathrm{HgCl}_{2}$ show cloudy swelling and coarse granular clumping of the cytoplasm suggestive of early liver changes. These liver findings were minimal in the animals sacrificed 8-12 hours after $\mathrm{HgCl}_{2}$ injection.

\section{DISCUSSION}

Serum LDH isozymes can be utilized to distinguish between liver and kidney damage in rats since liver damage results primarily in an increase in $\mathrm{LDH}-5$, while kidney damage results primarily in elevated levels of LDH-1 and -2. Cohen et al. (1964) reported similar findings in humans. Since these two organs are primarily targets in many types of chemical poisoning, the use of isozyme patterns in toxicologic investigations may become a most useful tool. It is apparent that although serum enzyme levels and isozyme 
patterns can provide useful information concerning sites of organ damage, it is necessary that conditions of blood collection and treatment of samples be uniform and carefully controlled.

The serum electrophoretic patterns obtained from rats after the ip injection of $\mathrm{HgCl}_{2}$ demonstrate several interesting findings. The increasing intensity of a new protein band in the $\gamma$-globulin region appears to coincide with a decrease in staining intensity of a band in the $\beta$-globulin area. It is tempting to speculate that the newly appearing protein could represent a mercury-protein complex which has a different electrophoretic mobility than the original protein. However, a similar protein shift due to cadmium was reported by Lawford (1961). In his studies no cadmium could be detected in the new protein. The actual migration of $\mathrm{Hg}$ from the $\alpha$-globulin fraction of protein to the albumin fraction was recently reported by Cember et al. (1968). The new protein band appears $8-12$ hours after $\mathrm{HgCl}_{2}$ injection, and by 24 hours is very pronounced. The lack of a similar protein band in animals whose organs were damaged by freezing suggests that this protein is not simply cellular protein arising from damaged tissue. Since mercury and other heavy metals can combine with sulf hydryl and other reactive biological groups, they may interfere with intracellular protein synthesis, causing incomplete or abnormal protein formation.

The $\mathrm{LDH}$ isozyme patterns in the present study of intraperitoneal $\mathrm{HgCl}_{2}$ poisoning suggest the early appearance of some liver damage which has cleared considerably 8-12 hours after injection. This is followed by the appearance at 12 hours of isozyme patterns characteristic of the kidney damage that one anticipates from $\mathrm{HgCl}_{2}$. The apparent early mild liver damage may be the result of the intraperitoneal injection of $\mathrm{HgCl}_{2}$ and direct uptake through the liver capsule. Histopathologic examination shows some slight evidence of both subcapsular and generalized parenchymal changes. However, mercuric chloride and mercuric acetate given orally produced elevations of serum LDH-5 1 hour after ingestion consistent with the results obtained by the ip route.

With the dosages of mercuric chloride utilized in the present study, the LDH isozyme pattern characteristic of kidney damage could be demonstrated approximately 12 hours after treatment. The ratio of $\mathrm{LDH}-1$ to $\mathrm{LDH}-2$ reached a ratio of approximately 1.0 at 25 hours after treatment and at the time of maximum serum activity. The higher ratios observed 48 and 72 hours after treatment, when total serum activity was decreasing, were probably related to the rate of loss of LDH-1 and LDH-2 activity. This would be consistent with the report of Boyd (1967), who demonstrated that the half-life of the LDH isozymes in the lamb became shorter in order from LDH-1 through LDH-5. Thus, LDH-5 had a half-life of only 7 hours compared with 48 hours for LDH-1 and 31 hours for LDH-2. The apparent low level of LDH-5, 48 and 72 hours after exposure, may also be partially explained by the short half-life and perhaps by a stimulation of inactivation mechanisms. Similar unusually low serum enzyme levels have been seen after initial high levels of other enzymes.

The present report illustrates the type of information that can be obtained with dosage variation and sequential serum isozyme patterns obtained after the ingestion of a toxic compound. Not only may the target organ be ascertained, but dose-response curves can be developed, and time lag in the development of organ damage may be studied. Such information may be important both to an understanding of the mechanism of toxicity and to the development and application of appropriate methods of treatment. 


\section{ACKNOWLEDGMENTS}

This investigation was supported in part by U.S. Public Health Service Grant GM-12854 from the National Institute of General Medical Sciences. The authors wish to thank Miss Dorothy Ketchum for her fine technical assistance in this study.

\section{REFERENCES}

Allen, J. M. (1961). Multiple forms of lactic dehydrogenase in tissues of the mouse. Ann. N.Y. Acad. Sci. 94, 937-951.

BoYD, J. W. (1967). The rate of disappearance of L-lactate dehydrogenase isoenzymes from plasma. Biochim. Biophys. Acta 132, 221-231.

Cember, H., Gallagher, P., and Faulkner, A. (1968). Distribution of mercury among blood fractions and serum proteins. Am. Ind. Hyg. Assoc. J. 29, 233-237.

Cohen, L., Djardievich, J., and Ormiste, V. (1964). Serum lactic dehydrogenase isozyme patterns in cardiovascular and other disease. J. Lab. Clin. Med. 64, 355-374.

DUNNETT, C. W. (1964). New tables for multiple comparisons with a control, Biometrics 20, 482-491.

KrAMER, C. Y. (1956). Extension of multiple range tests to group means with unequal numbers of replications. Biometrics 12, 307-310.

LAWFORD, D. J. (1961). An abnormal serum component in experimental poisoning by cadmium and other metals. Biochem. Pharmacol. 7, 109-122.

Reeves, A. L., Busby, E. K., and Scotti, L. (1967). Gel electrophoresis in the study of pneumoconioses. Am. Ind. Hyg. Assoc. J. 27, 278-287.

WEBB, E. C. (1964). Nomenclature of multiple enzyme forms. Nature 203, 821.

Wroblewski, F. and La Due, J. S. (1955). Lactic dehdrogenase activity in blood. Proc. Soc. Exptl. Biol. Med. 90, 210-213. 